\title{
Article \\ Long-Time Behavior of Surface Properties of Microstructures Fabricated by Multiphoton Lithography
}

\author{
Mateusz Dudziak ${ }^{1, *}$, Ievgeniia Topolniak ${ }^{1, *}$, Dorothee Silbernagl ${ }^{1}$, Korinna Altmann ${ }^{1}$ and Heinz Sturm ${ }^{1,2}$ (D) \\ 1 BAM Bundesanstalt für Materialforschung und -Prüfung, Unter den Eichen 87, 12205 Berlin, Germany; \\ dorothee.silbernagl@bam.de (D.S.); korinna.altmann@bam.de (K.A.); Heinz.Sturm@bam.de (H.S.) \\ 2 Institute for Machine Tools and Factory Operations (IWF), TU Berlin, Pascalstr. 8-9, 10587 Berlin, Germany \\ * Correspondence: mateusz.dudziak@bam.de (M.D.); ievgeniia.topolniak@bam.de (I.T.)
}

check for

updates

Citation: Dudziak, M.; Topolniak, I.; Silbernagl, D.; Altmann, K.; Sturm, H. Long-Time Behavior of Surface Properties of Microstructures Fabricated by Multiphoton Lithography. Nanomaterials 2021, 11, 3285. https://doi.org/10.3390/ nano11123285

Academic Editors: Konstantins Jefimovs and Ricardo Garcia

Received: 1 November 2021 Accepted: 29 November 2021 Published: 3 December 2021

Publisher's Note: MDPI stays neutral with regard to jurisdictional claims in published maps and institutional affiliations.

Copyright: (c) 2021 by the authors. Licensee MDPI, Basel, Switzerland. This article is an open access article distributed under the terms and conditions of the Creative Commons Attribution (CC BY) license (https:/ / creativecommons.org/licenses/by/ $4.0 /)$.

\begin{abstract}
The multiphoton lithography (MPL) technique represents the future of 3D microprinting, enabling the production of complex microscale objects with high precision. Although the MPL fabrication parameters are widely evaluated and discussed, not much attention has been given to the microscopic properties of 3D objects with respect to their surface properties and time-dependent stability. These properties are of crucial importance when it comes to the safe and durable use of these structures in biomedical applications. In this work, we investigate the surface properties of the MPL-produced SZ2080 polymeric microstructures with regard to the physical aging processes during the post-production stage. The influence of aging on the polymeric microstructures was investigated by means of Atomic Force Microscopy (AFM) and X-ray Photoelectron Spectroscopy (XPS). As a result, a time-dependent change in Young's Modulus, plastic deformation, and adhesion and their correlation to the development in chemical composition of the surface of MPL-microstructures are evaluated. The results presented here are valuable for the application of MPL-fabricated 3D objects in general, but especially in medical technology as they give detailed information of the physical and chemical time-dependent dynamic behavior of MPL-printed surfaces and thus their suitability and performance in biological systems.
\end{abstract}

Keywords: multiphoton lithography; microfabrication; SZ2080; Young's Modulus; aging; surface properties; X-ray photoelectron spectroscopy; atomic force microscopy; force distance curves

\section{Introduction}

Three-dimensional printing technologies have been gaining popularity for several decades due to their versatility, ease of use, and affordable prices. Nowadays, the most commonly used photoinduced 3D printing methods are Inkjet printing, Stereolithography (SLA), and Digital Light Processing (DLP) [1-3]. Despite the wide range of applications and inherent advantages of each technique, they still struggle with limited manufacturing control and insufficient resolution [4-6], often leading to objects with significant fragility [7,8]. The Multiphoton Lithography (MPL) technique has been shown to overcome most of these drawbacks. This state-of-the-art technique is based on the non-linear absorption of two or more photons, which enables polymerization in a small volume (voxel) of the photosensitive matter [9]. MPL is accurate and detailed due to its fine control of the fabrication process and non-linear nature, resulting in spatial resolution in the order of 0.1-1 $\mu \mathrm{m}$ [10]. This permits MPL to produce structures ranging in size from submicron [11] up to hundreds of micrometers [12,13]. Even higher pattern resolution can be achieved by applying the Stimulated Emission Depletion (STED) technique [14,15]. Currently, MPL is widely used in applications such as biotechnology [16], microelectronics [17], the semiconductors industry [18], and micro-optics [19,20]. Many organic, as well as inorganic-organic, hybrid materials are used as monomers [3]. The systems based on radical polymerization are (meth)acrylate-based [21], and thiol-ene and thiol-yne systems [22]. The addition of $\beta$-allyl 
sulfones $[23,24]$, as well as cationic systems, including azahelicenes, SU-8 or SCR-701, is also employed in MPL [25-27].

Applying NIR femtosecond laser in MPL makes it compatible with biological samples as this treatment is harmless to living research objects, including cells [28]. An example of using MPL technologies in bioengineering is presented by Koroleva et al. Scaffolds made of four-armed polylactic acid showed biocompatibility with human neural tissues. Moreover, it was evidenced that this photocurable material not only is non-toxic to neuronal cells, but also does not interfere with their proliferation and growth [29]. Therefore, this technique finds broad usage in the field of biophysics and biosystems. For instance, Psycharakis et al. used hybrid materials based on titanium and zirconium, and methacrylic acid as crosslinkable ligands to produce cellular scaffolds employing MPL. They showed that it is not only the chemistry of material but also the shape and layout of the structure that are crucial. The porosity of the printed material is extremely important in biological research as it allows for convenient cell proliferation, as well as their free expansion over the entire surface of the material [30]. Nevertheless, despite extensive investigations of 3D materials for biomedical application, time-dependent surface properties of MPL-fabricated microstructures have received very little attention. Commonly assumed to be constant with time, this important parameter is critical when it comes to the material application lifespan and dynamics of the polymer interactions with the applied biological environment.

Since surface properties, both physical and chemical, are crucial in the fields of bioengineering, the interaction of material and living matter has a significant impact on their applicability and suitability in bio-med systems. One of the strategies, as mentioned above, is chemical functionalization of the surface of MPL microstructures in order to achieve the desired performance. In this work, we report the details on surface aging, which should be taken into consideration for future approaches to alter microstructure properties and thus biocompatibility.

SZ2080 organic-inorganic hybrid photoresist is widely used in MPL due to its unique crosslinking properties [31]. It exhibits extra-low shrinkage during polymerization, resulting in negligible distortion of the printed structure [32]. The pre-clinical studies on MPL-fabricated SZ2080 microstructures demonstrated great biocompatibility of the scaffolds comparable to commercially available collagen membranes [33]. Being promising in the development of high-precision biocompatible structures, SZ2080 was selected for further investigation in the scope of this work.

Space-resolved characterization of the MPL microstructures is challenging and requires high-resolution methods with low material consumption. Among those are Atomic Force Microscopy (AFM) [34], X-ray Photoelectron Spectroscopy (XPS) [35], Transmission Electron Microscopy [36], Scanning Electron Microscopy (SEM), Small- and Wide-angle X-ray Scattering [37], and Flash Scanning Calorimetry [38]. To measure local mechanical properties of microstructures, AFM was employed to investigate polymers and nanocomposite surfaces [39], including MPL-structured material [40-42]. The measured volumes of mechanical measurements by means of AFM are typically in the range of $1 \mu \mathrm{m}^{3}$ or smaller, due to the small contact area between the AFM tip and applied forces that are in the range of $\mu \mathrm{N}$ during contact $[43,44]$ and can be used to determine micromechanical properties of materials such as their Young's Modulus, plastic deformation, and adhesion [45].

Herein, we focus on the characterization of surface properties of the SZ2080 polymer microstructures fabricated with the MPL technique. XPS and AFM force-distance curves (FDC) were used to monitor chemical and mechanical properties, respectively. The samples were examined during the time span of 25 days to determine physical and chemical changes at the surface. The obtained results on the time-dependent surface behavior of polymeric microstructures unraveled the guidelines for the reproducible and well-defined utilization of polymeric structures fabricated with MPL technique. 


\section{Materials and Methods}

\subsection{Materials and Sample Preparation}

SZ2080 negative photoresist (IESL-FORTH, Heraklion, Greece) containing $1 \mathrm{wt} \%$ of Michler's ketone photoinitiator was used in this work for MPL fabrication. A drop of the above-mentioned material was applied on the glass slip and heated, first at $60{ }^{\circ} \mathrm{C}$ for one hour, and afterwards at $100{ }^{\circ} \mathrm{C}$ for an additional hour. Next, a 3D microstructure was fabricated within the photoresist drop by applying MPL. After the fabrication process, the sample was immersed in the methyl isobutyl ketone (MIK, Sigma Aldrich, Taufkirchen, Germany) for one hour to remove the residue of unpolymerized material and then rinsed with the fresh portion of solvent a couple of times. The MIK solvent was used without prior purification. Finally, the obtained microstructure was dried in air and kept in the dark prior to further analysis at constant temperature and a relative humidity of $22{ }^{\circ} \mathrm{C}$ and $31 \%$, respectively.

\subsection{Methods}

\subsubsection{Multiphoton Lithography}

The 3D microstructures were produced with Laser Nano Factory (Femtika Ltd., Vilnius, Lithuania) and equipped with an Erbium-doped fiber laser (Menlo, Martinsried, Germany) emitting at $780 \mathrm{~nm}$ with a repetition rate of $100 \mathrm{MHz}$ for the used $100 \mathrm{fs}$ pulses. Beam focusing was performed by applying an oil-immersion objective with 1.4 numerical aperture (Plan Apochromat 63×, ZEISS, Jena, Germany). An array of repetitive and identical $30 \times 30 \times 30 \mu^{3}$ cubic structures was produced for AFM analysis. Structures of $2000 \times 1000 \times 5 \mu \mathrm{m}^{3}$ were fabricated for further characterization with XPS. All structures were obtained by applying the laser power and scanning velocity of $12 \mathrm{~mW}$ and $7000 \mu \mathrm{m} / \mathrm{s}$, respectively. The hatching and slicing distances were set at $0.2 \mu \mathrm{m}$ and $0.5 \mu \mathrm{m}$, respectively. Hatching direction alternated in $\mathrm{x}-\mathrm{y}$ directions with each layer. with each layer.

\subsubsection{Force Distance Curves Atomic Force Microscopy}

Atomic force microscopy (AFM) measurements were performed with an MFP-3D microscope (Oxford Instruments Asylum Research, Santa Barbara, CA, USA). The AFM was equipped with a Pointprobe NCL cantilever (Nanosensor, Wetzlar-Blankenfeld, Germany) with an elastic constant of $\mathrm{k}_{\mathrm{c}}=51.8 \mathrm{~N} / \mathrm{m}$ and a $\mathrm{Si}$ tip with a radius of approximately $\mathrm{R}=20 \mathrm{~nm}$, which was found by reference measurements on glass, which was assumed to have a Young's Modulus of $E_{\text {glass }}=72 \mathrm{GPa}$, a Poisson's ratio of $v=0.3$, and a resonant frequency $\mathrm{f}_{\text {res }}=340.8 \mathrm{kHz}$.

Force volume mode was used with a cantilever deflection trigger of $100 \mathrm{~nm}$ [46]. In addition, $10 \times 10 \mathrm{FDC}$ indentations were recorded on $10 \mathrm{\mu m}^{2}$ in the centric area of the microstructure's top surface, to be averaged for a better signal-to-noise ratio and to compensate for inhomogeneities of the surface [45]. The indentation frequency used is $1 \mathrm{~Hz}$.

AFM measurements were performed after one day post-fabrication and then carried out repeatedly until day 25 . For each measurement, an undeformed cube of the same batch was used. For reference purposes, glass was tested after each measurement of the sample in order to control both the geometry and the condition of the tip. Measurements on glass were found to be highly reproducible for the duration of the experiment, and hence the tip remained uncontaminated and sharp, as shown in Figures S1 and S2. All measurements were performed at room temperature.

From the averaged FDC, the overall mechanical behavior can be investigated, since both elastic and plastic deformations are recorded. In order to quantify plastic properties, typical features of the FDC are examined. In plotting the approach (red) and retract (blue) parts of the FDC in Figure 1, the large hysteresis is clearly visible. The reason for the hysteresis is that the sample stays deformed even after the tip and sample are detached, since it has been plastically deformed. As a measure for this property, we take the indent's depth $D_{\text {plastic }}$, which is the difference between the height of the surface at approach $\left(Z\left(\delta_{\text {approach }}=0\right) \equiv 0\right)$, and the height of the surface at retract $\left(Z\left(\delta_{\text {retract }}=0\right)\right)$. The 
plastic deformation of the sample reflects its softness, and hence the stability of the printed structure under loads. With softness in most polymeric materials also comes the ability to adhere to other surfaces. It can be quantified in the work of adhesion $W_{a d h}$, which is the work needed to detach the AFM probe from the sample surface. For that, the applied force $\mathrm{F}$ is calculated from Hooke's law:

$$
F=k_{c} \delta
$$

with $k_{c}$ being the spring constant of the cantilever and $\delta$ the deflection of the cantilever. In the plot of applied force $F$ versus piezo displacement $Z$, the work of adhesion $W_{\text {adh }}$ corresponds to the area of the jump off contact (JOC) of the retraction (blue curve), as shown in Figure 1.

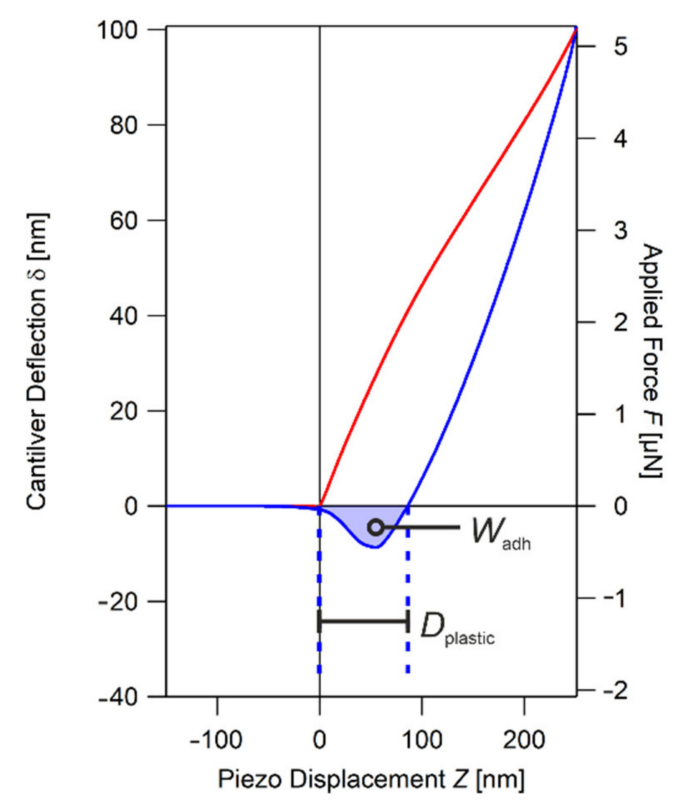

Figure 1. Averaged Force Distance Curve from MPL-fabricated SZ2080 microstructure at 25th day of post-fabrication. The red line corresponds to the approach part of the curve and the blue line to the retract part. The plastic properties are quantified by the plastic deformation $D_{\text {plastic }}$ and work of adhesion $W_{\text {adh }}$.

In order to determine the elastic properties of the printed structures, the deformation has to be calculated as follows:

$$
D=Z-\delta
$$

The reduced Young's Modulus $E^{*}$ can be now assessed by using the Hertz model:

$$
D=\left(\frac{F}{\sqrt{R} E^{*}}\right)^{\frac{2}{3}}
$$

where $D$ is the deformation, $F$ is the applied force, and $R$ is the tip radius.

Further, knowing the properties of the AFM tip and the reduced Modulus, the Young's Modulus can be determined by the following equation:

$$
\frac{1}{E^{*}}=\frac{3}{4}\left(\frac{1-v_{t i p}^{2}}{E_{t i p}}+\frac{1-v^{2}}{E}\right)
$$

where $v_{\text {tip }}$ is the Poisson's ratio of the tip (0.33), $v$ is the Poisson's ratio of the sample, $E_{t i p}$ is the Young's Modulus of the tip (225 GPa), and $E$ is the Young's Modulus of the sample. This model is only valid for elastic deformations [45,47]. 
As mentioned above, both elastic and plastic responses of the material are recorded by FDC. The elastic deformations are present at small applied forces; therefore, the Hertzian fit (Equation (3)) can be applied to the approach part of the FDC in order to calculate the Young's Modulus. At a certain mechanical load, $\mathrm{F}_{\text {yield, }}$, the material starts to yield and deforms irreversibly. The yield force $F_{y i e l d}$ is an important indicator for the mechanical stability of the material and thus is additionally assessed for each measurement, as shown in the Supplementary Materials (Figure S3).

\subsubsection{X-ray Photoelectron Spectroscopy}

X-ray Photoelectron Spectroscopy (XPS) analysis was performed with a spectrometer SAGE 150 (Specs, Berlin, Germany) equipped with a hemispherical analyzer Phoibos $100 \mathrm{MCD}-5$. The pressure in the analysis chamber was about $3 \times 10^{-7} \mathrm{~Pa}$, and nonmonochromatic AlK $\alpha$ radiation was used. The X-ray source is located at a $54.9^{\circ}$ angle to the lens system of the analyzer with the analyzer at $18^{\circ}$ to the surface at a vertical $90^{\circ}$. Identically prepared, freshly fabricated, and 25-day-aged samples were measured horizontally at $0^{\circ}$ in order to detect chemical changes that appeared during aging. In addition, the freshly printed sample was analyzed at three different flatter entry angles of the X-rays $\left(43.7^{\circ}, 53.7^{\circ}\right.$, and $\left.58.4^{\circ}\right)$, thus giving the information at shallower depths from the polymer surface. XPS spectra were collected in constant analyzer mode. The size of the measurement spot was about $1 \times 3 \mathrm{~mm}^{2}$, which is slightly larger than the pure sample area of $2000 \times 2000 \times 5 \mu \mathrm{m}^{3}$ but not problematic due to the titanium sample holder. Evaluation of the measured results occurred using CasaXPS. The C1s (as shown in Supplementary Figure S4) peak was standardized to the C-C peak at $285 \mathrm{eV}$ and deconvoluted. All C1s spectra were fitted according to the characteristic binding energies of $\mathrm{C}-\mathrm{C}(285 \mathrm{eV}), \mathrm{C}-\mathrm{O}$ $(286.5 \mathrm{eV}), \mathrm{C}=\mathrm{O}(288 \mathrm{eV})$, and $\mathrm{O}-\mathrm{C}=\mathrm{O}(289 \mathrm{eV})$.

\subsubsection{Scanning Electron Microscopy}

Material surface was analyzed with a Zeiss EVO MA 10 (Carl Zeiss Microscopy $\mathrm{GmbH}$, Jena, Germany) scanning electron microscope. The secondary electron mode with an acceleration voltage of $10 \mathrm{kV}$ was used to obtain the images.

\section{Results and Discussion}

\subsection{Topography of MPL Structures}

The accuracy of the fabrication can be observed in the SEM micrographs of SZ2080 cubic microstructures after AFM FDC analysis (Figure 2). Vertical and horizontal linear features that were produced by laser beam movement path can be detected. The print has been made in a repeatable manner.

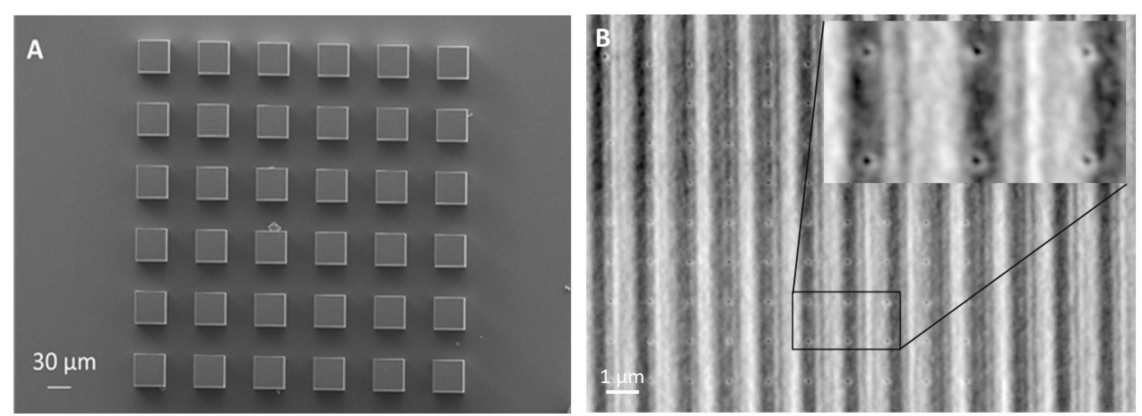

Figure 2. SEM micrographs of SZ2080 MPL-printed cubic structures used for time-dependent AFM investigation: (A) Array of identical cubes fabricated at the same MLP parameters. Each cube was used for only one AFM FDC measurement on a given day to avoid effect of the resulted structure artifacts on the further measurements. (B) Magnified surface of one of the cubes after AFM FDC measurement. Observed vertical line-like patterns are the result of printing procedure and correspond to laser scanning direction. Pointwise plastic deformations observed in a repetitive manner are caused by AFM FDC measurements. 
As can be seen in the SEM micrograph (Figure 2B), where the AFM indents are visible, FDC curves were taken on the sample surface with the tested area of $10 \times 10 \mu \mathrm{m}$. By averaging approximately 100 curves per measurement, it was assured that the topography artifacts and possible inhomogeneities, when present, do not contribute to the outcome of the data analysis.

\subsection{Mechanical Properties of the Surface}

The first FDC map was recorded $24 \mathrm{~h}$ after the SZ2080 structure was produced. Further, the series of FDC curves was recorded over the following 25 days and the corresponding $D_{\text {plastic, }} \mathrm{W}_{\text {adh }}, \mathrm{F}_{\text {yield, }}$, and Young's Moduli E of the surface were calculated. Figure 3 represents the detected changes in the sample deformation with respect to the applied force.

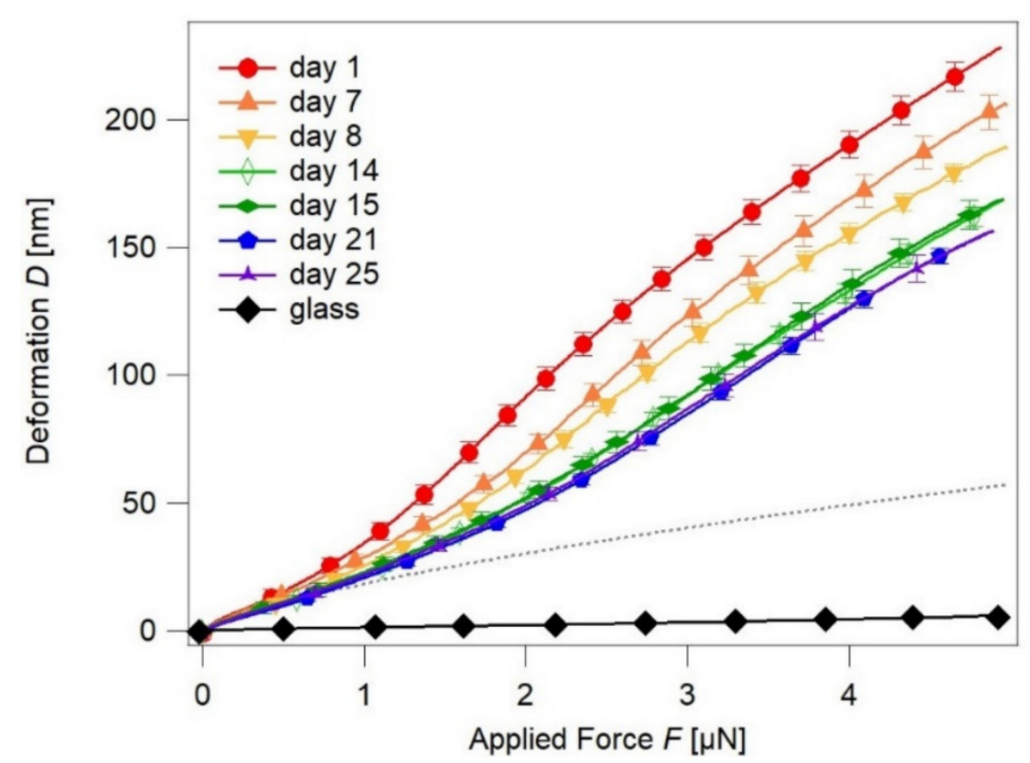

Figure 3. Mechanical properties of SZ2080 microstructures: material deformation depending on the applied force. Aging in the dark at the ambient temperature. The grey dotted line is an exemplary Hertz fit (Equation (3)) with $\mathrm{E}=1.3 \mathrm{GPa}$ and $\mathrm{R}=21 \mathrm{~nm}$, which only describes the elastic deformation. The experimental data show plastic deformation for forces $F>F_{\text {yield }}$, where the Hertz fit cannot describe the deformation.

One can observe that the maximum deformation $D_{\max }$ of the SZ2080 gradually decreases with the aging time and then stabilizes from the 14th day on. Measurements done at days 14 and 15 show the same results in the margin of error. One can then assume that changes of mechanical properties slow down with time. Therefore, the intervals between measurements were increased until properties stabilized, as can be seen for the results from days 21 and 25. The decrease in deformation rate over time is supported by an increase in the Young's Modulus. The Young's Modulus is assessed by Equation (3) for D(F = 0) < $\mathrm{D}<\mathrm{D}\left(\mathrm{F}_{\text {yield }}\right)$, with values rising by two times from 0.775 up to $1.3 \mathrm{GPa}$ (Table 1$)$. These values are in very good agreement with the previously published mechanical properties of SZ2080 (0.6-1.1 GPa) [48]. However, in the mentioned work, the effect of time on the mechanical properties was not pursued. The results in this study indicate a drastic change of the elastic properties of the SZ2080 microstructure surface during the first three weeks within the post-fabrication time. 
Table 1. Young's Moduli of the SZ2080 microstructures with respect to the post-fabrication time.

\begin{tabular}{cc}
\hline Post-Fabrication Period [Days] & Young's Modulus $E$ [GPa] \\
\hline 1 & $0.775 \pm 0.002$ \\
7 & $0.94 \pm 0.04$ \\
8 & $1.05 \pm 0.02$ \\
14 & $1.21 \pm 0.006$ \\
15 & $1.24 \pm 0.01$ \\
25 & $1.3 \pm 0.1$ \\
\hline
\end{tabular}

Further FDC analysis shown in Figure 4 identified mechanical load for plastic deformations $F_{\text {yield }}$, plastic deformation $D_{\text {plastic, }}$ and tip adhesion $W_{\text {adh }}$ in dependence of the post-fabrication time. An increase in $\mathrm{F}_{\text {yield }}$ of the polymer on consecutive days is observed in Figure 4A. As represented, from day one until day 14, the amount of the force increases and, afterwards, does not significantly change, indicating a plateau region. Meanwhile, $D_{\text {plastic }}$ of SZ2080 exhibits the reversed trend over the time (Figure 4B). As a result, one can observe a noticeable decrease in the plastic strain from $169 \mathrm{~nm}$ down to $88 \mathrm{~nm}$ for the first hours after printing and to the final days of the measurement, respectively. This implies that, during the first 14 days of experiment, the surface of the sample is more susceptible to plastic deformation that may indicate the softness and lower crosslinking degree of methacrylate groups.
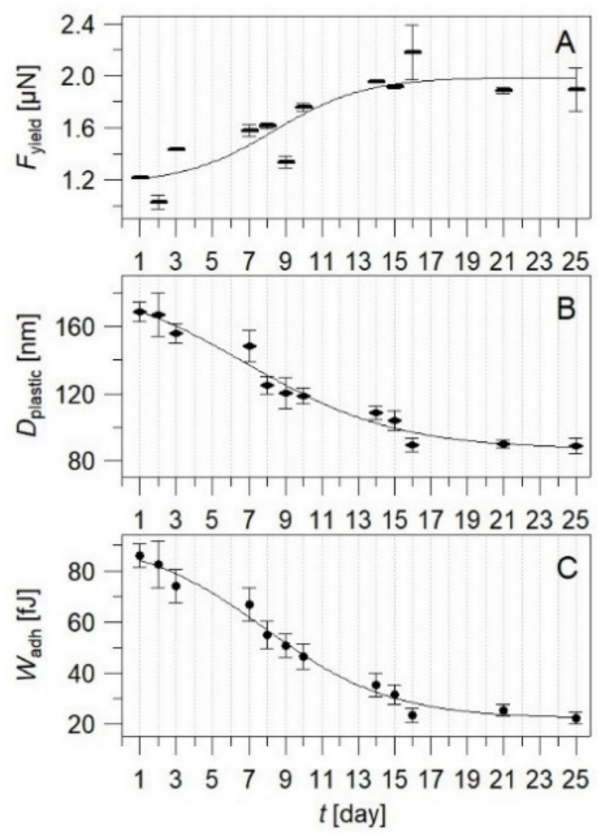

Figure 4. Mechanical properties of SZ2080 microstructures as a function of post-fabrication time: (A) mechanical load $\left(F_{\text {yield }}\right)$; (B) plastic deformations $\left(D_{\text {plastic }}\right)$ resulting from maximum applied force of $\mathrm{F}_{\max }=52 \mu \mathrm{N}$; (C) tip adhesion $\left(W_{\mathrm{adh}}\right)$ to the surface of measured structure. The black solid line is a sigmoidal fit for each data set.

We also observe that the AFM tip adhesion (Figure 4C) shows a similar tendency with the post-fabrication time as $\mathrm{D}_{\text {plastic }}$. The $\mathrm{W}_{\text {adh }}$ decreases during the first 16 days from 86 to $27 \mathrm{fJ}$ and, afterwards, remains in the range of 22-27 fJ. This indicates that the specimen undergoes significant changes of the surface, leading to a more constant nature of the surface properties and inertness towards the environment that is indicative of a loss of plasticity in favor of elasticity.

In order to quantify the post-fabrication time dependence of the plastic properties of SZ2080, a sigmoidal fit was applied to the data sets shown in Figure $4\left(\mathrm{~F}_{\text {yield }}, \mathrm{D}_{\text {plastic }}\right.$, and 
$\left.\mathrm{W}_{\mathrm{adh}}\right)$. From the sigmoidal fit, a conversion degree was calculated following the probability distribution of a bell curve, which is the derivative of a sigmoid (shown in Figure S5). The resulting values are gathered in Table 2 . As one can see, after 14 days $\mathrm{F}_{\text {yield }}$ has stabilized with $97.7 \%$ of the plateau value. However, plastic deformation and adhesion stabilize a little bit slower, reaching $97.7 \%$ of their final value after 19 and 18 days, respectively.

Table 2. Conversion degree of plastic mechanical properties of the SZ2080 microstructures with respect to the post-fabrication time in days. Following the integrated form of the empirical rule, the mean value $\mu$ equals $50 \%$ conversion degree and adding multiples of the standard deviation $\sigma$ equals 84.1, 97.7 , and $99.8 \%$ conversion degree.

\begin{tabular}{ccccc}
\hline & $\boldsymbol{\mu}$ & $\boldsymbol{\mu}+\boldsymbol{\sigma}$ & $\boldsymbol{\mu}+\mathbf{2 \sigma}$ & $\boldsymbol{\mu}+\mathbf{3 \sigma}$ \\
& $\mathbf{5 0 \%}$ & $\mathbf{8 4 . 1 \%}$ & $\mathbf{9 7 . 7 \%}$ & $\mathbf{9 9 . 8 \%}$ \\
\hline$F_{\text {yield }}$ & 8.4 & 12.2 & 14 & 19.8 \\
\hline$D_{\text {plastic }}$ & 6.9 & 12.9 & 18.9 & 24.9 \\
\hline$W_{\text {adh }}$ & 7.9 & 13 & 18.1 & 23.2 \\
\hline
\end{tabular}

Concluding from AFM FDC measurements, the surface of SZ2080 has shown dynamic behavior over time. The first 14-16 days after printing can be characterized by drastic changes in $\mathrm{F}_{\text {yield }}, \mathrm{D}_{\text {plastic}}, \mathrm{W}_{\mathrm{adh}}$, and Young's Modulus E. On the other hand, surface stabilization with a furthered aging period is observed and indicates a more inert stage of microstructure surface.

\subsection{Chemical Composition of SZ2080 Surface}

To better understand chemical changes underlying the observed stabilization of SZ2080 surface, MPL-fabricated samples were analyzed by means of XPS within $24 \mathrm{~h}$ after fabrication (initial state) and again once they reached 25 days (stabilized state) of post-fabrication time. One should keep in mind that XPS information typically corresponds to the first $5-7 \mathrm{~nm}$ of structure surface [49]. To access information at different penetration depths within the top $7 \mathrm{~nm}$ of the surface, additional angle-dependent measurements of the freshly prepared sample were performed, whereby the sample was placed at $43.7^{\circ}$, $53.7^{\circ}$, and $58.4^{\circ}$ from the X-ray source and compared to $0^{\circ}$ (horizontally flat) standard measurement. The obtained results are presented in Figure 5A and Supplementary Materials (Figure S5).

Deconvolution of the spectra of the fresh sample $\left(0^{\circ}\right.$ measurement, Figure S4) resulted in $85.2 \%$ for C-C and C-O groups of all the $\mathrm{C} 1 \mathrm{~s}$. Meanwhile, the carbonyl and carboxyl peaks were measured to be $6.7 \%$ and $8.1 \%$, respectively. This indicates oxidized hydrocarbons on the surface that probably come from aging processes in the contact of the surface with air. The chemical composition and molecular configuration of the SZ2080 structure is very complex; however, the simplified structure is suggested for ease of XPS data interpretation (Figure 5B). With an increase in the measurement angle (reduced information depth), the carbonyl peak increases from $20.3 \%\left(43.7^{\circ}\right)$ to $54.2 \%\left(58.4^{\circ}\right)$. At the same time, the carboxyl peak rises from $20.3 \%\left(43.7^{\circ}\right)$ to $23.9^{\circ}\left(53.7^{\circ}\right)$ and decreases to $5.4^{\%}$ at a $58.4^{\circ}$ measurement angle. That suggests a layer-like distribution of functional groups with the distance to the surface.

Most chemical changes due to aging are to be expected on the surface in the area of the SZ2080 organic functional groups. To investigate this effect, the C1s peaks of the freshly printed microstructure and the one after 25 days of post-fabrication time were compared by performing horizontal $\left(0^{\circ}\right)$ measurement. The obtained results are summarized in Table 3 . Comparison of the peaks corresponding to the binding energies of $\mathrm{C}-\mathrm{C}, \mathrm{C}-\mathrm{O}, \mathrm{C}=\mathrm{O}$, and $\mathrm{O}-\mathrm{C}=\mathrm{O}$ indicates the chemical modifications at the polymer structure with the increase in post-fabrication time. A significant decrease in the $\mathrm{C}=\mathrm{O}$ peak intensity with time signifies the post-curing process, and hence explains a decline in the surface adhesion observed with the AFM technique. In addition, an increase in C-O peak intensity from 1.6 to $12.9 \%$ is 
observed, whereas the peak corresponded to the C-C bond decreases in intensity by $6.2 \%$. Overall, the obtained results refer to two processes: on the one hand, further crosslinking of the molecules takes place through post-curing, and on the other hand, oxidation of the surface occurs. An increase in C-O amount in the SZ2080 surface structure can explain a decline in its adhesive properties during interactions with the AFM tip.
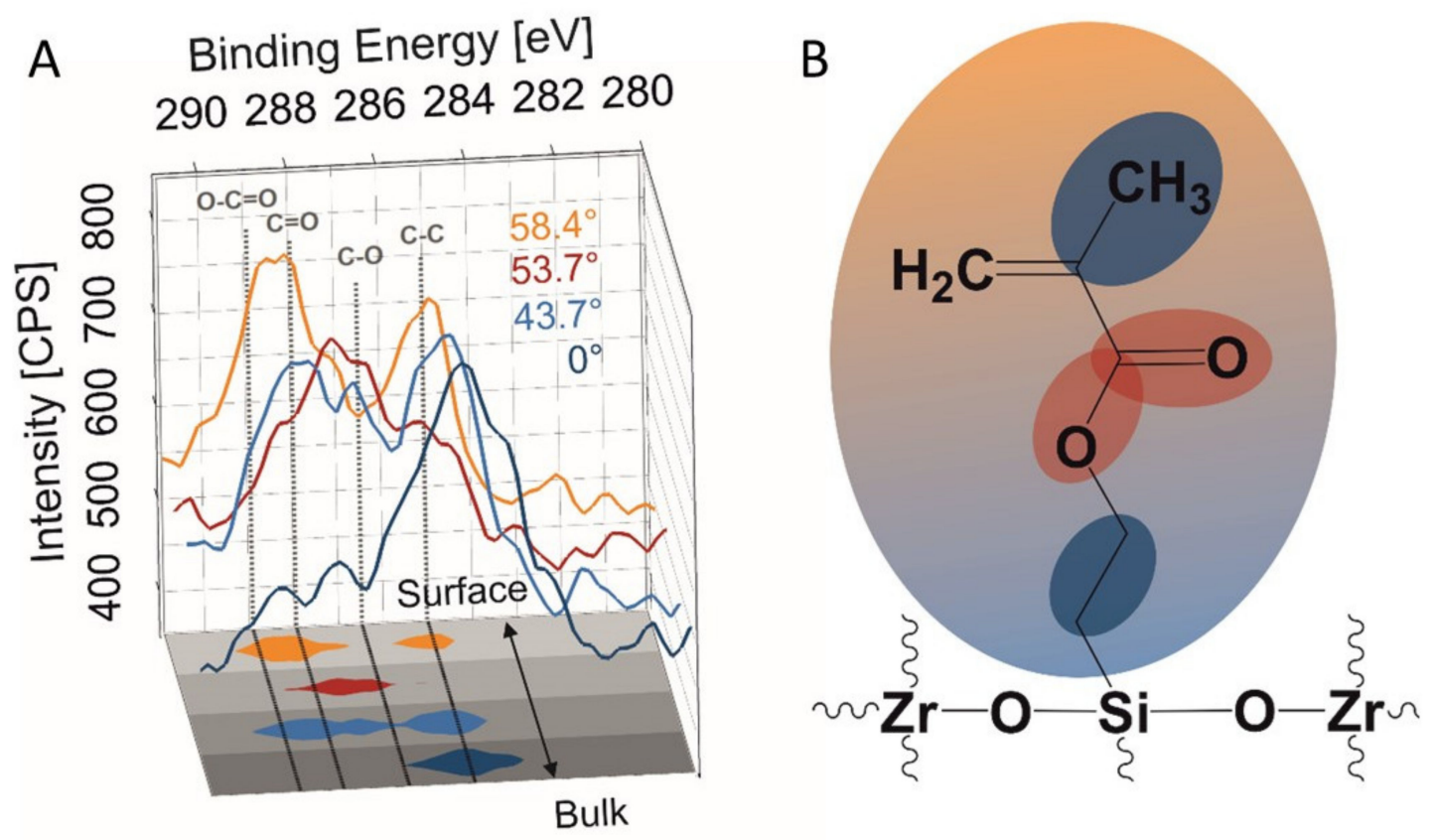

Figure 5. (A) Spatial representation of the C1s peak XPS spectra of different measurement angles (yellow $58.4^{\circ}$, red $53.7^{\circ}$, light blue $43.7^{\circ}$, and blue $0^{\circ}$ ). Peak areas (detected at Intensities $>635$ CPS) are projected on a scheme of sample depth (bottom of 3D plot). (B) Abstracted scheme of the surface composition as a function of the information depth of the fresh sample SZ2080. The selected colored ellipses represent the chemical groups detected by XPS.

Table 3. Percentage content of C1s-related chemical groups obtained from XPS spectra for SZ2080 microstructure at different post-fabrication times.

\begin{tabular}{ccccc}
\hline Functionality & C-C & C-O & C=O & O-C=O \\
\hline Binding energy [eV] & 285.0 & 286.5 & 288.0 & 289.0 \\
\hline Day 1 [\%] & 83.6 & 1.6 & 6.7 & 8.1 \\
\hline Day 25 [\%] & 77.4 & 12.9 & 1.8 & 7.9 \\
\hline
\end{tabular}

\section{Conclusions}

In summary, the time-dependent surface behavior of MPL-fabricated SZ2080 microstructures was investigated by means of AFM, FDC, and XPS. Consequently, the information on correlating Modulus, surface yield, adhesion, and chemical surface composition has been presented in this work. The observed process of surface aging during the postfabrication stage is defined by both mechanical and chemical changes. It was observed that the tip adhesion and plastic deformation decreased, while mechanical load and Young's Modulus increased during the first 14-16 days. In the period after 16 days, the physical properties of the surface stabilized, indicating final enhancement of the SZ2080 surface. The observed phenomena were underlined by chemical changes at the surface due to oxidation processes and crosslinking. To successfully apply SZ2080 microstructures, it is beneficial to employ printed structures at least 14 days after their fabrication to avoid disadvantageous interactions of the active groups of polymer surface with biological systems. Therefore, we suggest that structures with a post-fabrication time over 16 days would exhibit better 
properties in terms of biocompatibility. The approach proposed in this work might be another solution to expand the applicability of SZ2080.

Supplementary Materials: The following are available online at https:/ /www.mdpi.com/article/10 $.3390 /$ nano11123285/s1, Figure S1. Averaged FDC from reference measurements on glass: curves are highly reproducible throughout the whole experiment and in very good agreement with the Hertzian fit. Figure S2. Comparison of work of attractive forces during approach Wattr of glass and SZ2080 over time. As attractive forces of glass are fairly stable, indicating a clean tip with unchanged geometry, attractive forces of SZ2080 increase, an indication of increased density of the material at the surface of MLP-fabricated structures. Figure S3. Fyield is determined by the point of intersection of linear fits of the deformation D3/2 in the regime of elastic and plastic deformations. Figure S4. Deconvoluted representation of peaks of C1s for freshly printed sample at day 1 (A) and aged sample day 25 (B). Figure S5. Statistical analysis, including the bell curve with its characteristic areas $\mu$ and $\mu+\left(\mathrm{n}^{*} \sigma\right)$.

Author Contributions: MPL, I.T.; AFM investigation, M.D. and D.S.; writing-original draft preparation, M.D.; XPS investigation, K.A.; writing-review and editing, I.T., D.S., K.A. and H.S.; supervision, D.S. and H.S. All authors have read and agreed to the published version of the manuscript.

Funding: Financial support is acknowledged to the Deutsche Forschungsgemeinschaft (DFG, Grant Nrs 457594480 and 232311024).

Acknowledgments: We would like to address special thanks to Christiane Weimann for her help in SEM measurements.

Conflicts of Interest: The authors declare no conflict of interest.

\section{References}

1. Beedasy, V.; Smith, P.J. Printed Electronics as Prepared by Inkjet Printing. Materials 2020, 13, 704. [CrossRef]

2. Guo, Y.; Patanwala, H.S.; Bognet, B.; Ma, A.W.K. Inkjet and inkjet-based 3D printing: Connecting fluid properties and printing performance. Rapid Prototyp. J. 2017, 23, 562-576. [CrossRef]

3. Bagheri, A.; Jin, J.Y. Photopolymerization in 3D Printing. ACS Appl. Polym. Mater. 2019, 1, 593-611. [CrossRef]

4. Calvert, P. Inkjet printing for materials and devices. Chem. Mater. 2001, 13, 3299-3305. [CrossRef]

5. Minemawari, H.; Yamada, T.; Matsui, H.; Tsutsumi, J.; Haas, S.; Chiba, R.; Kumai, R.; Hasegawa, T. Inkjet printing of single-crystal films. Nature 2011, 475, 364-367. [CrossRef]

6. Cummins, G.; Desmulliez, M.P.Y. Inkjet printing of conductive materials: A review. Circuit World 2012, 38, 193-213. [CrossRef]

7. Tiller, B.; Reid, A.; Zhu, B.T.; Guerreiro, J.; Domingo-Roca, R.; Jackson, J.C.; Windmill, J.F.C. Piezoelectric microphone via a digital light processing 3D printing process. Mater. Des. 2019, 165, 107593. [CrossRef]

8. Lee, J.W.; Nahm, S.; Hwang, K.T.; Kim, J.H.; Kim, U.S.; Han, K.S. Synthesis and Characterization of Silica Composite for Digital Light Processing. Korean J. Mater. Res. 2019, 29, 23-29. [CrossRef]

9. Fang, F.H.; Aabith, S.; Homer-Vanniasinkam, S.; Tiwari, M.K. High-resolution 3D printing for healthcare underpinned by small-scale fluidics. In 3D Printing in Medicine; Woodhead Publishing: Cambridge, UK, 2017; pp. 167-206. [CrossRef]

10. Malinauskas, M.; Zukauskas, A.; Hasegawa, S.; Hayasaki, Y.; Mizeikis, V.; Buividas, R.; Juodkazis, S. Ultrafast laser processing of materials: From science to industry. Light. Sci. Appl. 2016, 5, e16133. [CrossRef] [PubMed]

11. Juodkazis, S.; Mizeikis, V.; Seet, K.K.; Miwa, M.; Misawa, H. Two-photon lithography of nanorods in SU-8 photoresist. Nanotechnology 2005, 16, 846-849. [CrossRef]

12. Park, S.H.; Yang, D.Y.; Lee, K.S. Two-photon stereolithography for realizing ultraprecise three-dimensional nano/microdevices. Laser Photonics Rev. 2009, 3, 1-11. [CrossRef]

13. Li, L.J.; Fourkas, J.T. Multiphoton polymerization. Mater. Today 2007, 10, 30-37. [CrossRef]

14. Maruo, S.; Nakamura, O.; Kawata, S. Three-dimensional microfabrication with two-photon-absorbed photopolymerization. Opt. Lett. 1997, 22, 132-134. [CrossRef]

15. Wollhofen, R.; Katzmann, J.; Hrelescu, C.; Jacak, J.; Klar, T.A. $120 \mathrm{~nm}$ resolution and $55 \mathrm{~nm}$ structure size in STED-lithography. Opt. Express 2013, 21, 10831-10840. [CrossRef]

16. Stankevicius, E.; Malinauskas, M.; Gedvilas, M.; Voisiat, B.; Raciukaitis, G. Fabrication of Periodic Micro-Structures by MultiPhoton Polymerization Using the Femtosecond Laser and Four-Beam Interference. Mater. Sci. 2011, 17, 244-248. [CrossRef]

17. Klein, S.; Barsella, A.; Leblond, H.; Bulou, H.; Fort, A.; Andraud, C.; Lemercier, G.; Mulatier, J.C.; Dorkenoo, K. One-step waveguide and optical circuit writing in photopolymerizable materials processed by two-photon absorption. Appl. Phys. Lett. 2005, 86, 211118. [CrossRef]

18. LaFratta, C.N.; Fourkas, J.T.; Baldacchini, T.; Farrer, R.A. Multiphoton fabrication. Angew. Chem. Int. Ed. 2007, 46, 6238-6258. [CrossRef] 
19. Pang, L.; Nakagawa, W.; Fainman, Y. Fabrication of two-dimensional photonic crystals with controlled defects by use of multiple exposures and direct write. Appl. Opt. 2003, 42, 5450-5456. [CrossRef] [PubMed]

20. Guo, R.; Xiao, S.Z.; Zhai, X.M.; Li, J.W.; Xia, A.D.; Huang, W.H. Micro lens fabrication by means of femtosecond two photon photopolymerization. Opt. Express 2006, 14, 810-816. [CrossRef] [PubMed]

21. Jasinski, F.; Zetterlund, P.B.; Braun, A.M.; Cherntob, A. Photopolymerization in dispersed systems. Prog. Polym. Sci. 2018, 84, 47-88. [CrossRef]

22. Husar, B.; Ligon, S.C.; Wutzel, H.; Hoffmann, H.; Liska, R. The formulator's guide to anti-oxygen inhibition additives. Prog. Org. Coat. 2014, 77, 1789-1798. [CrossRef]

23. Gorsche, C.; Griesser, M.; Gescheidt, G.; Moszner, N.; Liska, R. beta-Allyl Sulfones as Addition-Fragmentation Chain Transfer Reagents: A Tool for Adjusting Thermal and Mechanical Properties of Dimethacrylate Networks. Macromolecules 2014, 47, 7327-7336. [CrossRef]

24. Gorsche, C.; Koch, T.; Moszner, N.; Liska, R. Exploring the benefits of beta-allyl sulfones for more homogeneous dimethacrylate photopolymer networks. Polym. Chem. 2015, 6, 2038-2047. [CrossRef]

25. Al Mousawi, A.; Dumur, F.; Garra, P.; Toufaily, J.; Hamieh, T.; Goubard, F.; Bui, T.T.; Graff, B.; Gigmes, D.; Fouassier, J.P.; et al. Azahelicenes as Visible Light Photoinitiators for Cationic and Radical Polymerization: Preparation of Photoluminescent Polymers and Use in High Performance LED Projector 3D Printing Resins. J. Polym. Sci. Pol. Chem. 2017, 55, 1189-1199. [CrossRef]

26. Greer, A.I.M.; Vasiev, I.; Della-Rosa, B.; Gadegaard, N. Fluorinated ethylene-propylene: A complementary alternative to PDMS for nanoimprint stamps. Nanotechnology 2016, 27, 155301. [CrossRef]

27. Yu, T.Y.; Ober, C.K.; Kuebler, S.M.; Zhou, W.H.; Marder, S.R.; Perry, J.W. Chemically amplified positive resists for two-photon three-dimensional microfabrication. Adv. Mater. 2003, 15, 517-521. [CrossRef]

28. Ovsianikov, A.; Muhleder, S.; Torgersen, J.; Li, Z.Q.; Qin, X.H.; Van Vlierberghe, S.; Dubruel, P.; Holnthoner, W.; Redl, H.; Liska R.; et al. Laser Photofabrication of Cell-Containing Hydrogel Constructs. Langmuir 2014, 30, 3787-3794. [CrossRef] [PubMed]

29. Koroleva, A.; Gill, A.A.; Ortega, I.; Haycock, J.W.; Schlie, S.; Gittard, S.D.; Chichkov, B.N.; Claeyssens, F. Two-photon polymerization-generated and micromolding-replicated 3D scaffolds for peripheral neural tissue engineering applications. Biofabrication 2012, 4, 025005. [CrossRef]

30. Psycharakis, S.; Tosca, A.; Melissinaki, V.; Giakoumaki, A.; Ranella, A. Tailor-made three-dimensional hybrid scaffolds for cell cultures. Biomed. Mater. 2011, 6, 045008. [CrossRef]

31. Malinauskas, M.; Zukauskas, A.; Bickauskaite, G.; Gadonas, R.; Juodkazis, S. Mechanisms of three-dimensional structuring of photo-polymers by tightly focussed femtosecond laser pulses. Opt. Express 2010, 18, 10209-10221. [CrossRef]

32. Ovsianikov, A.; Viertl, J.; Chichkov, B.; Oubaha, M.; MacCraith, B.; Sakellari, I.; Giakoumaki, A.; Gray, D.; Vamvakaki, M.; Farsari, M.; et al. Ultra-Low Shrinkage Hybrid Photosensitive Material for Two-Photon Polymerization Microfabrication. ACS Nano 2008, 2, 2257-2262. [CrossRef]

33. Maciulaitis, J.; Deveikyte, M.; Rekstyte, S.; Bratchikov, M.; Darinskas, A.; Simbelyte, A.; Daunoras, G.; Laurinaviciene, A.; Laurinavicius, A.; Gudas, R.; et al. Preclinical study of SZ2080 material 3D microstructured scaffolds for cartilage tissue engineering made by femtosecond direct laser writing lithography. Biofabrication 2015, 7, 015015. [CrossRef] [PubMed]

34. Khorasani, M.G.Z.; Silbernagl, D.; Szymoniak, P.; Hodoroaba, V.D.; Sturm, H. The effect of boehmite nanoparticles (gamma$\mathrm{AlOOH})$ on nanomechanical and thermomechanical properties correlated to crosslinking density of epoxy. Polymer 2019, 164, 174-182. [CrossRef]

35. Wurzler, N.; Sobol, O.; Altmann, K.; Radnik, J.; Ozcan, O. Preconditioning of AISI 304 stainless steel surfaces in the presence of flavins-Part I: Effect on surface chemistry and corrosion behavior. Mater. Corros. 2021, 72, 974-982. [CrossRef]

36. Jedrzejczak-Silicka, M.; Trukawka, M.; Dudziak, M.; Piotrowska, K.; Mijowska, E. Hexagonal Boron Nitride Functionalized with Au Nanoparticles-Properties and Potential Biological Applications. Nanomaterials 2018, 8, 605. [CrossRef] [PubMed]

37. Smales, G.J.; Pauw, B.R. The MOUSE project: A meticulous approach for obtaining traceable, wide-range X-ray scattering information. J. Instrum. 2021, 16, P06034. [CrossRef]

38. Szymoniak, P.; Qu, X.T.; Abbasi, M.; Pauw, B.R.; Henning, S.; Li, Z.; Wang, D.Y.; Schick, C.; Saalwachter, K.; Schonhals, A. Spatial inhomogeneity, interfaces and complex vitrification kinetics in a network forming nanocomposite. Soft Matter 2021, 17, 2775-2790. [CrossRef] [PubMed]

39. Cuenot, S.; Fretigny, C.; Demoustier-Champagne, S.; Nysten, B. Surface tension effect on the mechanical properties of nanomaterials measured by atomic force microscopy. Phys. Rev. B 2004, 69, 165410. [CrossRef]

40. Bayindir, Z.; Sun, Y.; Naughton, M.J.; LaFratta, C.N.; Baldacchini, T.; Fourkas, J.T.; Stewart, J.; Saleh, B.E.A.; Teich, M.C. Polymer microcantilevers fabricated via multiphoton absorption polymerization. Appl. Phys. Lett. 2005, 86, 064105. [CrossRef]

41. Belqat, M.; Wu, X.Y.; Gomez, L.P.C.; Malval, J.P.; Dominici, S.; Leuschel, B.; Spangenberg, A.; Mougin, K. Tuning nanomechanical properties of microstructures made by 3D direct laser writing. Addit. Manuf. 2021, 47, 102232. [CrossRef]

42. Buchroithner, B.; Hartmann, D.; Mayr, S.; Oh, Y.J.; Sivun, D.; Karner, A.; Buchegger, B.; Griesser, T.; Hinterdorfer, P.; Klar, T.A.; et al. 3D multiphoton lithography using biocompatible polymers with specific mechanical properties. Nanoscale Adv. 2020, 2, 2422-2428. [CrossRef]

43. Cappella, B.; Silbernagl, D. Nanomechanical properties of mechanical double-layers: A novel semiempirical analysis. Langmuir 2007, 23, 10779-10787. [CrossRef] 
44. Cappella, B.; Silbernagl, D. Nanomechanical properties of polymer thin films measured by force-distance curves. Thin Solid Films 2008, 516, 1952-1960. [CrossRef]

45. Butt, H.J.; Cappella, B.; Kappl, M. Force measurements with the atomic force microscope: Technique, interpretation and applications. Surf. Sci. Rep. 2005, 59, 1-152. [CrossRef]

46. Silbernagl, D.; Khorasani, M.G.Z.; Murillo, N.C.; Elert, A.M.; Sturm, H. Bulk chemical composition contrast from attractive forces in AFM force spectroscopy. Beilstein J. Nanotechnol. 2021, 12, 58-71. [CrossRef] [PubMed]

47. Garcia, R. Nanomechanical mapping of soft materials with the atomic force microscope: Methods, theory and applications. Chem. Soc. Rev. 2020, 49, 5850-5884. [CrossRef]

48. Pertoldi, L.; Zega, V.; Comi, C.; Osellame, R. Dynamic mechanical characterization of two-photon-polymerized SZ2080 photoresist. J. Appl. Phys. 2020, 128, 175102. [CrossRef]

49. Oswald, S.; Bruckner, W. XPS depth profile analysis of non-stoichiometric NiO films. Surf. Interface Anal. 2004, 36, 17-22. [CrossRef] 